\title{
MEGA-SPORT EVENTS, MICRO AND SMALL BUSINESS LEVERAGING: INTRODUCING THE “MSE-MSB LEVERAGE MODEL”
}

\author{
SETH I. KIRBY,* MICHAEL B. DUIGNAN,† AND DAVID MCGILLIVRAY $\ddagger$ \\ *Lord Ashcroft International Business School, Anglia Ruskin University, Cambridge, UK \\ †School of Marketing and Management, Coventry Business School, Coventry University, Coventry, UK \\ $\ddagger$ School of Media, Culture and Society, University of the West of Scotland, Paisley, UK
}

\begin{abstract}
Micro and small business (MSB) interests legitimize mega-sport event (MSE) candidature bids. Yet, MSB interests can be sidelined in the event lead up, live staging, and legacy periods. This article provides a detailed: 1) review of MSE impacts on existing MSBs residing within targeted host communities, 2) conceptual and practical examination of MSE leveraging opportunities, 3) synthesis of good inclusionary practices identified in previous MSE case studies. As a result, a series of general and specific ways MSEs can foster MSB leveraging and legitimize local interests are suggested. We present a comprehensive analysis of key works since mid-1990s related to the themes identified above. Our analysis identifies that there is limited conceptual and empirical research on MSB impact and leveraging activities in the context of MSEs, yet significant evidence points to negative experiences, disruption, and displacement effects on residential (host) communities. We purposively focus on good practice in the context of other MSEs from the Olympics Games (e.g., London 2012, Rio 2016) and FIFA World Cup (e.g., South Africa, 2010) to inform recommendations and managerial implications. We outline a systematic series of ways MSBs can be structurally excluded from accessing MSE leveraging opportunities. Building on Chalip’s widely adopted event leverage model (ELM), we present the "MSE-MSB Leverage Model” to illustrate how MSEs can (re)position MSBs as legitimate stakeholders to support greater leveraging opportunities and better (re)distribute event benefits back into host communities across planning and delivery stages. These range from reconfiguring: 1) event planning principles and policies, 2) regulatory and trading environments, and 3) the development of MSB business-to-business networks and partnerships.
\end{abstract}

Key words: Host community; Mega-sport event (MSE); Micro and small business (MSB); Leveraging; Event management; Event planning and policy

Address correspondence to Seth I. Kirby, Doctoral Researcher and Associate Lecturer, Lord Ashcroft International Business School, Anglia Ruskin University, East Road, Cambridge, CB1 1PT, UK. E-mail: seth.kirby@anglia.ac.uk 


\section{Introduction}

From local cultural activities right through to large-scale commercial, global sporting extravaganzas like the Olympic Games, events manifest themselves in a range of sizes and with diverse impacts. Mega-sport events (MSEs) like the Olympic Games and FIFA Football World Cup serve as major tools for global cities to stimulate economic outcomes, due to the international scale of their target visitor markets and associated media interest (Roche, 2017). Yet, over recent years, major concerns have been expressed over the hyper-inflated claims made for MSEs and the gap between overly optimistic economic forecasts and actual impacts (Horne \& Whannel, 2016). The ways in which prospective hosts bid, plan, and deliver MSEs is tied up with other strategic development activities to help them establish or (re)assert their global status and secure regional economic gains, through the valuation and creation of a portfolio of events (Getz, 2017; Gration, Raciti, Getz, \& Andersson, 2016). Project plans are complicated by the cross-cutting multiplicity of stakeholder interests-some convergent and others divergent to the central objectives of MSEs (Faulkner et al., 2000). In other words, some interests, like micro and small businesses (MSBs) within host communities can be rendered “invisible” (Raco \& Tunney, 2010), although their inclusion in the earlier phases of bidding and project planning is often central to the justification of MSEs. Grix, Brannagan, Wood, and Wynne (2017) claimed that a "coalition of beneficiaries" (p. 2) interests are prioritized, often including externalcontingent stakeholders like the International Olympic Committee (IOC) and Olympic family of corporate sponsors. Event organizers are faced with a very real dilemma: does the foregrounding of "local" interests detract from, or jeopardize, the exclusivity arrangements promised to official sponsors, suppliers, and supporters whose resources fuel financial strategies of MSEs? A central question of this article is the extent to which existing MSBs are recognized within this tight-knit coalition, and perhaps more pertinently, whether MSBs can be conceived of as a stakeholder at all.

Proponents of MSE development stress the capacity of such projects to transform targeted areas
(Smith, 2012). Achieving developmental outcomes quickly and efficiently is down to the MSEs ability to catalyze existing, and stimulate new, urban policy at the international, national, regional, and local level (Swart \& Bob, 2004). The Olympic 2020 Agenda (IOC, 2018) forces current and future host cities and decision makers (e.g., National Olympic Committees, NOCs) to drive (ethically) normative values and outcomes as extolled and demanded by the virtuous aims of the global governing body IOC's Olympic Charter and overarching Olympic Movement. Horne and Whannel (2016) argued that prospective MSE hosts play to fairness ideals in the bidding and early stages of planning, emphasizing consultation and negotiation. By doing so, they project a rhetoric of immediate (positive) outcomes and a legacy of empowering and building capacity for locals, including MSBs, across host communities - rarely acknowledging the potential for marginalization. This drive for positive outcomes is central to legitimizing the project especially in light of significant (on-going) critique that MSEs are speculative projects (Lauermann, 2014) that invisibilize less-desirable local neighborhoods (Raco \& Tunney, 2010; Steinbrink, 2013).

Nevertheless, uneven developmental outcomes as illuminated by the Organization for Economic Cooperation and Development (OECD, 2008) have led to a trend of prospective host city populations vetoing bids, and candidature cities withdrawing (Bason \& Grix, 2018). Kassens-Noor and Lauermann (2017) argued that event organizers must tackle structural and systematic exclusionary conditions brought to bear by the coming of MSEs, particularly the negative impacts faced by existing MSBs, including limited access to Olympic supply chains and visitor economies (e.g., Celik, 2011; Heere, Van Der Manden, \& Van Hemert, 2015). In this article we are concerned with 1) reviewing the extant literature to identify how MSB interests can be included and/or excluded, 2) examining the mechanisms that event organizers may wish to use to help MSBs better leverage event opportunities, and 3) proposing ways to (re)position MSBs as legitimate stakeholders (Donaldson \& Preston, 1995) across the planning and delivery of MSEs. The article is guided by two overarching research questions: 
RQ1: How are micro and small business (MSB) interests included or excluded in the planning and delivery of mega-sport events (MSEs)?

RQ2: What practical mechanisms can event organizers present and promote to support MSB legitimacy and leveraging in the context of MSEs?

Structurally, we begin by outlining how existing MSBs can be impacted by the coming of MSEs, followed by a review of practical and conceptual notions of leveraging. We then shift our attention to how competing stakeholder interests have been previously managed in MSE contexts, drawing out good practices to inform the practical mechanisms required to achieve RQ2. We fuse our examination of impacts, leveraging, and good practice to support MSB legitimacy and leveraging activities by creating a "MSE-MSB Leverage Model” that can be used across multiple phases (bidding and selection; planning; delivery and handover), building on Chalip's (2004) widely adopted event leverage model (ELM). Theoretical and practical management implications close the article, alongside suggestions for future academic study.

\section{Reviewing the State of the Art: MSE and MSB Impacts}

Firstly, we used a desk-based review to identify and analyze the current state of the art on MSB impacts and their relationship to MSE bidding, planning, and delivery. This review enabled an examination of the role and involvement of MSBs across MSE planning and delivery. In other MSE research, this technique has been adopted as a suitable approach to classifying themes (e.g., Foley, McGillivray, \& McPherson, 2012; C. Jones, 2001). For sake of parsimony, we focused on specific key word searches (e.g., "mega-event," "business," "impact," and "leverage") across two key databases: EBSCOhost Business Source Premier and Elsevier Science Direct, uncovering a total of 173 articles. The search was conducted on March 12, 2018. Other well-known publishers, including Taylor \& Francis, SAGE, Wiley, Emerald Insight, and Ingenta Connect were then mined, yielding a further 48 articles. Results were filtered based on their relevance to the specific unit of analysis informing this article (e.g., MSBs). Those articles selected for review fulfilled a number of search criteria, in both the abstract and full text. For example, we sought to determine whether articles considered the impacts of MSEs on individual or groups of MSBs (e.g., hotels, tour operators). Articles that mentioned local business were questioned further to establish the scope of their investigations. Studies that explicitly directed their attention towards small enterprise organizations were retained (e.g., Rogerson, 2009). The MSB impacts concentrated on were hospitality, retail, and tourism- and travelrelated MSBs, residing within affected host communities. Table 1 includes the final list of relevant articles, including those that prioritize MSEs, but also including other major sporting events like the Commonwealth Games. Although not exhaustive, the authors attempted to include prominent works and cases published since the mid-1990s. Table 1 includes reference to the nature of impact claimed, evidence of leveraging being discussed alongside the type of article and its publication date. Effectively, our examination of the state of the art illustrates that little academic study has focused on specific MSB impacts and leveraging activities in the context of MSEs, presenting an opportunity for this article to contribute. Exploring this gap in knowledge is vital when juxtaposed against concerns of host community marginalization-yet most studies focus on experiences, disruption, and displacement of residential stakeholders, with little focus on MSBs.

\section{A Damning Report Card: Excluding Micro and Small Business Interests}

Our review of MSB impacts and leveraging (see Table 1) indicates a gap in the literature; however, based on the evidence presented in the studies accessed, there is evidence of the exclusion of host communities and MSBs as a stakeholder group within the MSE research environment. Casting our focus back to the mid-1990s, business impact assessments emerged with Mount and Leroux's (1994) and Spilling's (1996, 1998) examinations of the 1988 Calgary Olympic Games and 1994 Lillehammer Olympic Games, respectively. These 


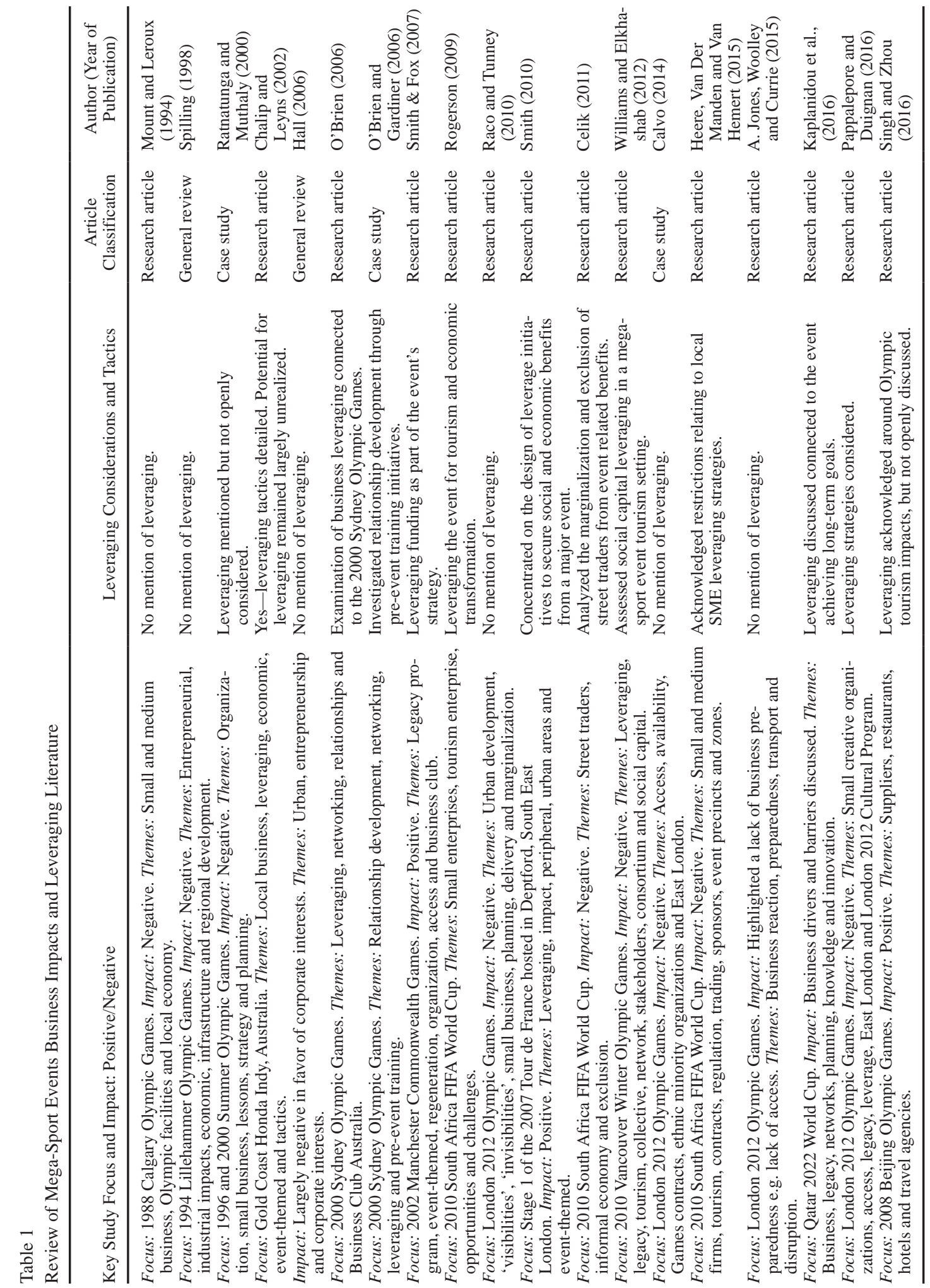


studies expressed doubts over the appropriateness of MSEs as a driver for longer-term sustainable regional growth-building on emergent concerns over disruption and displacement effects faced by residential communities in the wake of the Los Angeles 1984 and Barcelona 1992 Olympic Games (e.g., Gold \& Gold, 2008). Ratnatunga and Muthaly (2000) suggested that poor organizational structure and the limited operational and strategic capabilities of MSBs precluded them from fully accessing and realizing potential leverageable opportunities from MSEs. Since then, academic scholars (Chalip \& Leyns, 2002) and policy makers (e.g., London Assembly, 2006) have recognized the structural challenges MSBs face when attempting to leverage benefits from event opportunities.

For some time, major international and national governmental and nongovernmental agencies including the House of Lords (2013) and the OECD (2008) have derided MSEs like the Olympic Games for foregrounding elite stakeholder interests and producing uneven and unequal socioeconomic outcomes. Significant conceptual and empirical evidence exists to suggest that the interests, needs, and demands of host community stakeholders have become deprioritized across MSE planning and delivery (e.g., Raco \& Tunney, 2010). Before the Olympic Games, Raco and Tunney (2010) and Steinbrink (2013) identified how host communities are frequently disrupted, pacified, depoliticized, or even forcefully removed from localities (displaced) to make way for necessary urban and event infrastructure. During the Olympic Games, McGillivray and Frew (2015) and Pappalepore and Duignan (2016) identified that host communities become subject to "states of exceptions"-bound by securitization and militarization force, alongside the erection of new commercial event zones and venues at the heart of existing residential and small business communities, precluding access to local leveraging opportunities (from event-related visitor economies to supply chain opportunities). These event-specific regulations include restricted access to urban public spaces (e.g., squares and streets) deployed as MSE venues (Smith, 2018). After the Olympic Games, the House of Lords (2013) and the OECD (2008) identified the pervasive risk of rising residential and commercial rents, leading to gentrification-led displacement as a result of place marketing and enhanced destination desirability — often referred to as the "Olympic effect" (House of Lords, 2013). The more spectacular elements of event planning and adjoining multinational interests frequently render locally situated MSB interests “invisible” and deprioritized.

That MSB interests are deprioritized is at odds with their importance to the national and regional economies of MSE hosts. At past MSEs, including the 2012 and 2016 Olympic Games and the 2014 FIFA Football World Cup, MSBs made up a substantial proportion of employment and economic output in these cities and nations. For example, at the start of 2012 London-based SMEs accounted for $99.8 \%$ of all businesses in the city, represented nearly half $(49.8 \%)$ of total London employment and generated $(48 \%)$ of all business turnover (Department for Business, Innovation \& Skills, 2012). As of the end of 2013, Brazilian small businesses generated over half (52\%) of total employment, according to the Brazilian micro and small business support service (SEBRAE, 2015). Despite their central role in bolstering local economic output, evidence suggests there are numerous cases of MSBs being left behind and unable to accrue the expected tangible or intangible gains from event hosting. For example, MSE regulations imposed in advance of the 2010 South Africa World Cup served to restrict local MSB leveraging strategies, rendering them unable to take advantage of event commercial opportunities, including profit generation and partnership building that could have led to sustainable outcomes (Heere et al., 2015). A. Jones, Woolley, and Currie (2015), in the context of London 2012, advanced a similar argument about the limited business "preparedness" (e.g., lack of resources), and ability to react and alleviate the challenges associated with such determined MSEs environments.

Alongside exclusionary conditions during the pre-Games and live staging phases, a significant body of evidence from governmental and nongovernmental organizations points to the systemic pressures MSEs impose on local business communities (e.g., House of Lords, 2013). Hall (2006) echoed these sentiments, claiming that MSB interests continue to be overshadowed by macro, global corporate demands, leading to local exclusion. For example, regarding the 2006 Germany Football 
World Cup, Nicholas Stucke, President of the German Trade Association, quoted in Hall (2006) suggested that “there won't be any German products on sale in the marketplaces of the towns where the matches are being held. . . . You can get a CocaCola, American Beer, and McDonalds but that will be it ... German products will be locked out" (p. 61). Empirical evidence from the London Olympics in 2012 demonstrated that MSEs produced widespread exclusion of local business populations. This related to the lack of access and availability of Olympic Games-specific contract opportunities (Calvo, 2014; Pappalepore \& Duignan, 2016). In the case of London 2012, UK firms through online portals such as CompeteFor won $98 \%$ of over $£ 6$ billion worth of Olympic Delivery Authority contracts (UK Trade \& Investment [UKTI], 2013). Yet only $12 \%$ of small businesses from a Federation of Small Businesses (FSB) post-Games survey said that they had worked on an official contract for the Olympic Games (FSB, 2013). To sum up, the review of existing literature on MSB impacts from MSEs suggests that they are often marginalized, unable to influence decision making, and precluded from fully exploiting visitor economy opportunities as a result of the strict demands laid down by awarding bodies when the host city contracts are signed. Corporate partners take precedence over the interests of local MSBs and these arrangements have to be materialized in event delivery by the local organizing committee. However, this does not necessarily mean that MSBs cannot access opportunity and be fully integrated into future MSE plans. In the next section we discuss how the concept of strategic leveraging represents a more effective way of embedding the interests of MSBs in the MSE planning and delivery processes.

\section{Event Leveraging and Micro and Small Business Inclusion}

Leveraging in the context of sporting events is associated with the works of Chalip (2004), Chalip and Leyns (2002), O’Brien (2006), and O’Brien and Gardiner (2006). Chalip and Leyns' (2002) study focused on business managers, experts, and business leaders' views on local business leveraging tactics. Conceptually, leveraging refers to a planned, strategic, and resourced investment in activities using the context of a MSE as a catalyst (Chalip, 2004; McPherson, Misener, McGillivray, \& Legg, 2017). O’Brien (2006) and O’Brien and Gardiner (2006) examined business leveraging strategies at the Sydney 2000 Olympic Games, exploring dimensions including relationship development and networking through preevent training initiatives. Their work inspired the introduction and spread of the premise and possibilities of business clubs or networks (e.g., Business Club Australia initiative). Since then, scholars have advanced the role of business networks by ascertaining how pre- and postlegacy MSE programs can forge and engage business club and business network opportunities (e.g., Kaplanidou, Al Emadi, Sagas, Diop, \& Fritz, 2016; Smith, 2010; Smith \& Fox, 2007). Kaplanidou et al. (2016) established how business legacy goals and networking impacts were linked to areas such as new knowledge generation, innovation, and technology change. The development of strategic business-to-business (B2B) consortiums have been central to leveraging activities and MSB inclusion. For example, Williams and Elkhashab (2012) outlined leveraging benefits from a tourism consortium at the 2010 Vancouver Winter Olympic Games.

Although evidence from the state of the art review suggests that MSEs exacerbate exclusionary practices, recent literature suggests that, if leveraged strategically, there are opportunities to use MSEs to accelerate priority developments to the benefit of local businesses and enterprises-aligning with existing policy goals rather than contradicting them. For leveraging tactics to be effective, the literature suggests that strategic intervention early on in the process, and targeted event planning, is required to promote wider inclusion and access to trade opportunities (e.g., Olympic Games contracts), in this case for MSBs. An early exponent of event leveraging, Chalip (2004) aptly outlined a number of vital MSE leveraging opportunities, for example, fostering and managing the alliances of local enterprises, business associations, and government agencies to extend local supply chains, generate joint promotions, and build new markets. Chalip's (2004) model envisaged driving a destination's portfolio of events as a leverageable asset and resource. An event portfolio approach is advocated by a range of stakeholders (e.g., consortiums inclusive of 
businesses and local authorities) to leverage potential immediate and longer-term gains. It is argued that event leveraging can foster this emergent overall portfolio of activities across cities, primarily through physical, digital, and place branding attributes and schemes (Duignan, Kirby, O’Brien, \& Everett, 2018). In doing so, this could help to achieve and maximize the tangible and intangible MSB opportunities that hosting MSEs presents.

Our review also illustrates that capitalizing on the small business leveraging potential of MSEs is still in its infancy. In the MSE context, the coordinated planning of business leveraging entails local businesses developing their promotional strategies and tactics, jointly in line with the strategic objectives of the event, organizers, and destinations' marketing campaign. This is an important consideration for raising the profiles of MSBs through engaging with the event's brand and relationships across the project. Businesses are integral stakeholders with identifiable stakes and rewards that can be sought from working collaboratively to exploit business opportunities in the host destination (Chalip \& Leyns, 2002). Yet, the literature suggests that poor operational, marketing and strategic business skills can hamper small businesses from optimizing event leveraging opportunities (e.g., Chalip \& Leyns, 2002; Faulkner et al., 2000).

A critical requirement of event leveraging is how to accommodate an eclectic mix of stakeholders. Integrating this mix of stakeholders from local authorities to business groups and MSBs and creating networking areas may support the possibility of realizing favorable outcomes, particularly through access to dedicated physical spaces for MSB leverage (Bason \& Grix, 2018; Duignan et al., 2018). This is significant as MSEs can mobilize the possibilities of planned and unplanned business exchanges, as well as assisting with relationshipbuilding activities for small businesses to leverage the B2B opportunities for long-term economic success (O’Brien, 2006; O’Brien \& Gardiner, 2006). For example, MSEs provide the foundation for businesses to generate new contacts and build relationships between suppliers and buyers (Chalip, 2004). Similarly, leveraging city bidding business networks can be useful, whereby local firms and internationally known corporate resources are combined (Bason \& Grix, 2018). Leveraging a holistic approach to events and examining how the local city organizers (e.g., local organizing committee and authority) manage the leveraging process is critical to facilitating a strategic portfolio, as well as augmenting businesses attractiveness. Therefore, capturing the essence of immediate and longer-term opportunities for improving entrepreneurial capabilities of the host is advantageous in aiding MSB outcomes. For leveraging to provide real benefits, prospects relate to how plans can be feasibly formulated to incorporate local populations (e.g., MSBs) and amplify widespread beneficial outcomes.

Central to our argument is the position that MSBs could be better legitimized, positioned, and therefore factored into key aspects of planning and delivery. We outline a series of opportunities as to how MSEs could do this in the next section. These ideas, alongside a plethora of other good practices are identified from other case studies and integrated into our "MSE-MSB Leverage Model.”

\section{Leveraging Micro and Small Business Opportunities}

Building on Chalip's (2004) ELM model, in Figure 1 we present the MSE-MSB Leverage Model. The model includes a synthesis of all analyses presented in the above sections, aligned with the conceptual tenets of the ELM model, overlaid with examples of good practice identified from other event contexts. We focus on tactics and strategies to inform practical mechanisms, concentrating on the core themes of: 1) event planning and policies; 2 ) regulation and trading environments; and 3 ) networks and partnerships. These themes are embedded across bidding, planning, and delivery to produce a series of actionable steps that MSE organizers can implement to legitimize, (re)position, and support greater leveraging efforts by MSBs.

Leverageable Phase: Bidding and Selection. In the lead up to a prospective host city deciding whether or not to submit a formal application to bid, working relationships and informal commitments have already been forged between a temporary bid committee and potential partners-whether sponsors, local and national governments, and sporting federations (McGillivray \& Turner, 2017). Bid 


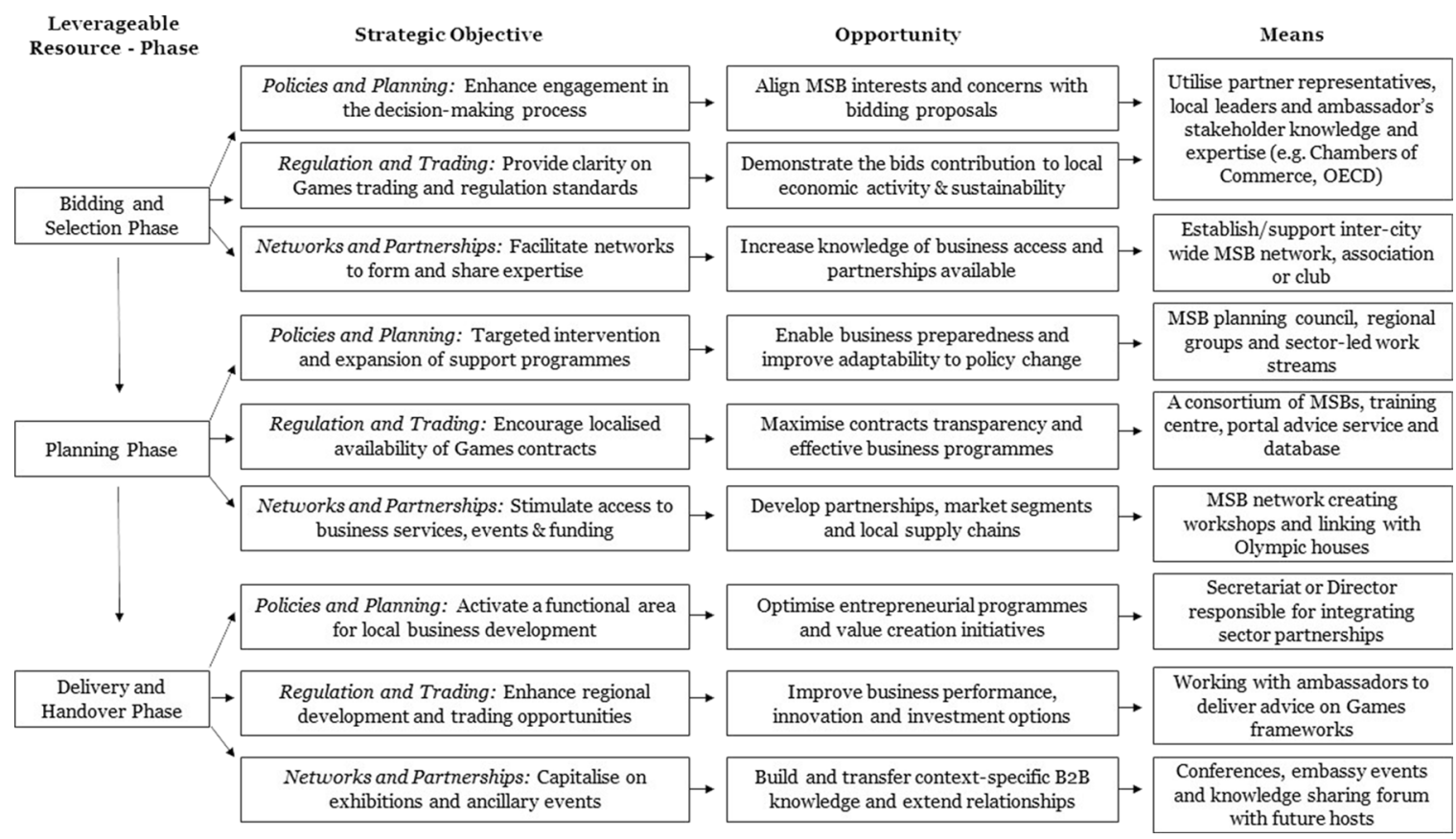

Figure 1. MSE-MSB Leverage Model [adapted from Chalip’s (2004) original model].

teams are normally public-private coalitions (e.g., local/national government, policy makers) competing to secure the hosting contract from the event owners, including the IOC (Bason \& Grix, 2018; Lauermann, 2014) and FIFA. Having a seat at the table during the bid process is critical if a clearer and stronger voice for MSBs is to be sustained once the bid has been won. Once the host city has been awarded with the rights to execute the event, agreements housed within the host city contract force a number of obligations onto the host, which must be attended to-some of which act against the interests of MSBs. The involvement of MSBs and their representative organizations (e.g., Chambers of Commerce) can lead to benefits for the hosts. These organizations possess expertise, knowledge, and access to a network of local leaders and ambassadors that can mobilize support during the event bidding phase. At this stage, MSBs can lack the skills to plan strategic activities and suitably position their brand (Ratnatunga \& Muthaly, 2000).

To address these issues and ensure that MSB interests are foregrounded at this leverageable phase, it is imperative that the policy and planning process involves MSB engagement in decisionmaking processes. This could include utilizing MSB partner representatives, local leaders, and ambassadors with knowledge and expertise (e.g., small business groups, Chambers of Commerce, the OECD) to galvanize support and lobby for the representation of MSB views. The opportunity at this stage is to ensure that the bid processes include a commitment to demonstrate how the proposed bid will contribute to local economic activity and sustainability. For example, before London 2012, one of the Department for Culture, Media \& Sports' (DCMS) ambitions was to "contribute to increasing and sustaining growth in UK business, including small to medium-sized enterprises" (DCMS, 2008, p. 61). Likewise, the Queensland Government (2017) emphasized how the 55,000 small businesses across the Gold Coast could tap into the opportunities of hosting the 2018 Commonwealth Games through their Be Games Ready program, and Advancing Small Business Queensland Strategy.

Working collaboratively and engaging MSBs and their representative organizations may secure a greater percentage of supply contracts for MSEs. 
As identified earlier, according to the FSB, only around $12 \%$ of small businesses worked on official London 2012 Games contracts (FSB, 2013). Therefore, perhaps pushing for a target figure of at least 25\% awarded to MSBs could be a step in the right direction. Additionally, bringing together a consortium of MSBs to increase their capacity to deliver a local food offer could be another solution. During negotiations over the host city contract, local organizers may propose that a proportionate amount of the food offerings are supplied by local food and drink suppliers and caterers, similar to the strategy of the Glasgow 2014 Commonwealth Games (Glasgow 2014 XX Commonwealth Games, 2014a). For the networks and partnerships theme, organizers could look to facilitate networks to form and share expertise. Commencing at the bid stage, a city-wide MSB business network, association, or club may produce an opportunity to coordinate programs with the assistance of business working groupsenabling event knowledge to be exchanged and a stronger lobbying or advocacy role to be pursued. With the help of local (government) authorities, a business network, association, or club could be created to increase business adoption of such initiatives (Smith \& Fox, 2007). Harnessing the (local) possibilities brought to bear by a new transient mega-event led visitor economy, hospitality, and catering leveraging are key sectors to be exploited. Yet, accessing such opportunities are a challenge for MSBs due to issues of red tape (i.e., health and safety procedures, and procurement rules) and their potential inability to deliver such large contractual obligations. We argue that developing consortiums, B2B networks, with support from event organizers and local authorities are central to overcoming such challenges.

Leverageable Phase: Planning. Once MSE bids are won, evidence suggests that it is much more difficult to affect change and influence the decisionmaking process (Shaw, 2008). However, during the planning phase, there remains some significant opportunities for targeted interventions that can benefit MSBs. For example, local business networks possessing an understanding of the Games trading conditions, agreements, and business support programs can aid business preparedness for such an event (A. Jones et al., 2015). The creation of a MSB planning council, sector-led work streams, or regional groups of representatives may provide a forum for discussion and propose solutions to local issues (e.g., planned business relocation) linked to infrastructure projects. Planning councils could be tasked with upskilling MSBs and assisting with the creation of nonprofit groups or cooperatives. These may be purposely designed to support specialist business programs (on themes including business operations and productivity), achieved through involvement in local business networks. Public sector departments have the potential to facilitate the participation of local business through a MSB consortium, training centers, portal advice services, and a supply and tender database. An open, accessible, and accountable application, tendering database and review process also enables the assessment of MSB requirements. Enhancing transparency in the allocation of contracts and increasing the number of local business contracts may provide MSBs with an opportunity to deliver contracts for specific Games "live sites.” In terms of the delivery of contracts, it is acknowledged that procurement rules in Europe and globally could prevent the prioritization of "local" over global actors. However, in sectors (e.g., food and beverage, tourism, and hospitality) this may not impinge upon the opportunities, which may be deemed more notable, compared to the management of procurement contracts for major infrastructural projects. The CompeteFor platform implemented for London 2012 was regarded as a success in promoting better supplier diversity and accountability in the awarding of contracts. In this case, the FSB recognized CompeteFor as a "model of enabling and assisting small businesses to bid for and win procurement contracts” (FSB, 2013, p. 11). Even then, research has emphasized a range of barriers were faced by small ethnic minority organizations in attempting to register with the website portal (Calvo, 2014).

A MSB city association or club provides options for forums and workshop provision. This relates to supporting business services and resources, such as local authority public funding, access to supplier frameworks, and entrepreneurial initiatives. As argued in the bidding and selection phase, 
representative organizations for MSBs need to be around the table and, when opportunities to "localize" the event present itself (e.g., food provision, dressing the local neighborhoods, business programs) then MSBs can be prioritized. Engagement through these channels could garner better MSB participation in the event planning processes. In the run up to MSEs, the MSB network could have a base or headquarters around the host city, such as pavilions or "Olympic houses."

Preparing and supporting local business through meaningful engagement has been demonstrated in cases, such as at the 2014 Glasgow Commonwealth Games and the Gold Coast 2018 Commonwealth Games (GC2018). Firstly, Glasgow hosted "Get Ready Glasgow" information and engagement events for businesses. A range of events covered businesses information sessions, partner events and meetings, business breakfasts between public and private sector organizations, and the development of a portal to enable businesses to compete for public-private sector contracts in the city (Glasgow 2014 XX Commonwealth Games, 2014b). Furthermore, there was a dedicated site and social media platforms set up, incorporating the Glasgow Major Events Group on LinkedIn. This provided access to visitor information, to identify and plan opportunities, engage with the event organizers, and develop partnerships (Glasgow 2014 XX Commonwealth Games, 2014b). GC2018 have introduced similar sets of initiatives from a Get Set for the Games business guide, to industry specific business workshops, information pop-up sessions to breakfast mornings-like the Get Set Breakfast Short (Gold Coast 2018 Commonwealth Games Corporation, 2018). Examples, particularly from Glasgow 2014, indicate that, with strategic foresight, planning, and a commitment to the interests of local businesses, benefits can be derived for the event and the businesses themselves.

Leverageable Phase: Delivery and Handover. At the delivery phase, the Local Organizing Committee could provide and activate a functional area or employ a Director who sits on the committee with a defined responsibility for advocating MSB benefits. This could be part funded by the local state, replicating positions at Glasgow 2014, like the Director of Engagement and Legacy (Glasgow 2014 XX Commonwealth Games, 2014c). The role could be dedicated to preparing or advising local businesses, managing MSB relationshipsbridging Games delivery and host legacy environments. Using this functional area, local business needs and services may be identified and entrepreneurial programs optimized for improving business performance, value creation, and availability of investment options. A secretariat or Director as stated above could be responsible for integrating publicprivate sector partnerships with MSBs to enhance regional business development opportunities. In practice, local authorities may be able to establish joint programs with other regions, which support MSBs to connect and strengthen collaborative projects, scale up the development of their business, and share best practice. NOC's and governments could effectively integrate public-private business partnerships or introduce ambassador programs to build Games frameworks and retain the expertise and knowledge of local organizations (LockstoneBinney, Whitelaw, Robertson, Junek, \& Michael, 2014). Furthermore, working with ambassadors and partner organizations can support partnership working with other smaller and larger organizations.

To harness business networks and partnerships an incentivized project fund may be allocated for local businesses to create "content" and products outside of official Games venues. This MSBoriented fund program provides the means for small businesses to showcase their products and services, and capitalize on Games expos, conferences, and smaller ancillary events. At an intercity and regional level, these events offer the opportunity for collective knowledge and expertise to be shared through business groups, consortiums, and commercial associations. For instance, creating smaller working groups and streams focused on a range of issues (e.g., technology, public engagement) across certain industries to proficiently impart and distribute valuable context-specific knowledge, toolkits, and innovations.

Productive approaches for generating B2B opportunities are also evident with respect to longerterm business networking. For example, Smith and Fox's (2007) review into the 2002 Commonwealth Games in Manchester lauded the successes of the legacy program, including the creation of the 
North West Business Club and other opportunities for businesses in the North West of England, for example, increased business access to online services, exhibitions, and funding to run events. During the hosting of London 2012 there were opportunities for businesses to engage with new networks and build relationships incorporating sites like purpose-built venues or embassies. The now defunct government department, UK Trade \& Investment (UKTI), established the British Business Embassy hosted at Lancaster House, London. According to the UKTI (2013), in the run up and during the Olympic Games, the British Business Embassy held a global investment conference and 17 specialist business sector events, attended by 4,000 delegates, such as 800 international business delegates from 63 countries. From figures released back in 2013, the Embassy supposedly induced $£ 5.9$ billion of additional sales from Olympicrelated activity (UKTI, 2013). At this stage, there is an opportunity for MSBs to use the network(s) as a mechanism for building capabilities and competencies (e.g., human capital, knowledge sharing), and cultivating enduring business partnerships across a range of industries. Local businesses may be able to transfer newly acquired tangible (e.g., financial) and intangible (e.g., people development) skills to improve business efficiency, positioning, or branding. This can be achieved using conferences and embassy events to develop knowledge, skills, and extend relationships. Moreover, local organizers might instigate a knowledge-sharing forum between previous and future hosts with a specific “module” or taskforce on MSB opportunities.

At recent MSEs, there is some evidence of the partial involvement of small businesses in the food and beverage sector, predominantly in and around official event zones (e.g., Duignan \& McGillivray, 2016). For example, Duignan and McGillivray's analysis of official event precincts across Rio's host city illustrated how Live Site and Last Mile spaces afforded opportunities for micro and small business inclusion, coupled with exploiting the presence of large crowds to trade. At Glasgow 2014, MSBs in the food and beverage sector benefited from the organizers' commitment to a food charter encapsulating a local and sustainable food and drink offer. As a result, these businesses were able to work cooperatively with the local council and organizing committee to ensure the food and drink available in their Live Zones were sourced locally. Glasgow's food sourcing code built on the best practice procurement frameworks introduced for London 2012. Developed in 2009, the framework of the London Organizing Committee of the Olympic and Paralympic Games (LOCOG) was considered to be a ground-breaking food vision and Sustainable Sourcing Code (LOCOG, 2009). In Glasgow, as part of the Food Charter the organizers devised a sustainable Food Sourcing Code highlighting four core themes. The code contained guidance on promoting equal opportunity for purchasing arrangements and a procurement provision encouraging a broader appeal to the widest number of suppliers, as well as practices underpinned by rigorous Scottish benchmarking standards for quality assurance and food safety (Glasgow 2014 XX Commonwealth Games, 2014a). This group of blueprints demonstrated a custom-built, forward thinking, and innovative approach to sustainable sourcing and local business inclusion, which has since been extended and remodeled for GC2018-taking the form of the Catering Functional Area (C.A.T.F.A) sourcing standard. The aim of this new standard is to incentivize MSBs to establish a more sustainable regional food culture (Gold Coast 2018 XXI Commonwealth Games, 2017). In light of evidence gathered from a number of recent MSEs, Table 2 provides suggestions for a future research agenda, which assesses how the complex dynamics of MSEs can be planned and executed with MSB inclusion in mind. A specific set of applied and practical actionable steps have been outlined to balance MSB inclusivity, amplify MSB stakeholder interests, help redistribute the bounties of MSEs, and consider how critical issues (e.g., MSB marginalization and lack of access of opportunity) associated with MSEs can be remediedacross all three main phases of delivery (before, during, and postevent).

\section{Conclusions}

In this article we have outlined the persistent, overarching challenge of MSB exclusion in relation to MSEs. Our detailed review of the extant literature on MSE and MSB impacts identified good practices that may be leveraged for future events. 
Table 2

Future Research Agenda for Balancing MSE-MSB Demands and Inclusivity

\begin{tabular}{lll}
\hline Theme & Event Phase and Process $\quad$ Prospect for MSB Benefit(s)
\end{tabular}

Event Planning • Bidding and Selection: Utilizing partner representa- •

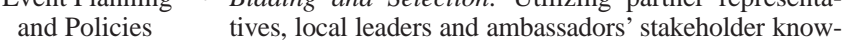
ledge and expertise (e.g., Chambers of Commerce, OECD, 2008). During the event bidding phase these representative organizations possess knowledge and provide access to a network of ambassadors to mobilize support (e.g., Lockstone-Binney et al., 2014). This is an underexplored area in MSE policymaking.

- Planning: Event support programs through an MSB planning council, regional groups and sector-led work streams. Creating smaller working groups and streams focused on a range of issues (e.g., technology) across specific industries is critical for driving innovative tools and practices for MSB.

- Delivery and Handover: Secretariat or Director responsible for integrating public-private sector partnerships. Defining a functional area in the Local Organizing Committee, authority, or government dedicated to advising MSB proposals.

Regulation and Trading

Environments

- Bidding and Selection: A commitment to demonstrate how the proposed bid will contribute to local economic activity and propel the requirements for a sustainable event cities framework (Getz, 2017).

- Planning: A consortium of MSBs, training centers, portal advice service and supply and tender database.

- Delivery and Handover: MSB working with ambassadors to deliver advice on Games frameworks. In MSE analysis, the pervasive restrictions and management of local MSB access to urban public spaces (e.g., 'live sites' or 'fan parks') require a detailed empirical program to investigate these impacts (Smith, 2018).
MSB Benefit - Bidding and Selection: Ensuring that MSB voices are suitably represented, and aligning MSB interests and concerns with bidding proposals, development plans and policies.

- MSB Benefit - Planning: Enabling business preparedness caused by Olympic Games trading conditions and agreements (A. Jones et al., 2015), and improving adaptability to policy change.

- MSB Benefit - Delivery and Handover: Optimizing entrepreneurial programs and value creation initiatives for MSB to improve their business productivity.
- MSB Benefit - Bidding and Selection: Incorporating MSB communities into the Games bidding plans may be beneficial for encouraging the spread of responsible business practices, sustainability policies and corporate social responsibility (CSR) programs, as emphasized by London 2012's Sustainable Sourcing Code (LOCOG, 2009).

- MSB Benefit - Planning: Enhancing transparency in the allocation of contracts and increasing the number and effectiveness of local business programs. By linking with partners to accommodate MSBs in the negotiations of industry and trading standards and contracts for the Games (e.g., supply and tender agreements).

- MSB Benefit - Delivery and Handover: Enabling micro and small businesses to enhance their recognition, take advantage and tap into the short term and prolonged commercial profit generating activities that MSEs induce (e.g. tourism and immediate leverageable regional trade opportunities).

Networks and Partnerships
- Bidding and Selection: With the help of the local authority, establishing or supporting an inter-city wide MSB network, association or club designed to increase business access (Smith \& Fox, 2007). There is a real shortage of evidence concerning how MSEs can influence MSB network creation activities.

- Planning: MSB network creating workshops and forming associations with Olympic houses. For example, forums, advice workshops, seminars and training sessions supplying information and developing MSB knowledge and skills (e.g., writing bids/grant applications and contract negotiation).

- Delivery and Handover: Extending conferences, embassy events and a knowledge-sharing forum between previous and future hosts with a specific MSB "module." MSB knowledge sharing between MSE hosts is notably absent in the literature.
- MSB Benefit - Bidding and Selection: Increase knowledge of MSB access and partnerships available, and provide a platform or marketplace for MSB to trade.

- MSB Benefit - Planning: Supporting partnership working, developing MSB market segments and local supply chains. MSB may link with 'Olympic houses' around the city, in addition to preparing a base nearby preevent training camp locations to strengthen collaboration (e.g., national team training camps).

- MSB Benefit - Delivery and Handover: Close knit collaboration and developing new contacts and relationships with other small traders and suppliers and global event partners may lead to further engagement and the sharing of experiences. Through event and exhibition channels, MSB could identify potential links with business associations and programs built as a result of the Games e.g., integration with the destination management organization's (DMO) strategies. Bundling MSB strategies and working with key players such as the tourism authority is a topic worthy of attention. 
The current state of the art indicated there is a dearth of research on MSB impact and leveraging activities in the context of MSEs, identifying a number of prominent challenges facing MSBs. These challenges include unequal trickle down and distribution of Games-related opportunities, organizational issues and concerns, erosion of access to Games contracts, and regulatory restrictions. Presently, these challenges are inhibiting MSBs from benefiting from the hosting of MSEs. We propose that strategic leveraging be a better tactic employed by MSE organizers and their state partners to enhance MSB access and engagement. Untapped leveraging opportunities include the harnessing of business networks (e.g., business clubs, consortiums), possessing a clear, coordinated strategic events portfolio plan, and the development and maintenance of B2B relationships and collaborations.

To support the redistribution of benefits to MSB, this article offers actionable ways stakeholder planning and outcomes can be more inclusive and evenly balanced across the whole lifecycle of MSEs (bidding, planning, and delivery) for MSB communities. A model for leveraging MSB opportunities was suggested to (re)position local MSBs as legitimate stakeholders. The "MSE-MSB Leverage Model” developed is an extension of Chalip's (2004) ELM, associated with the phases of MSEs. This multistage model focuses on capitalizing on the small business leveraging potential of MSEs across three core themes_-event planning and policies, regulation and trading environments, and networks and partnerships.

Analysis presented across the article illustrates MSB stakeholder interests, needs, and objectives can be amplified and engaged before, during, and postevent. This is particularly vital as MSEs promote narratives of local inclusion, but often fail to meet the needs and interests of local businesses. As a result, such inclusive agendas may help MSEs create more sustainable local MSB outcomes into the legacy phase and adhere to the very "fairness ideals" awarding bodies like the IOC claims to abide by. Currently, there is very little evidence to suggest that MSEs are in fact "fair" and "equitable" in their distribution of leverageable opportunities and that the real benefits are weighted in favor of those who possess the elite networks to access the types of development opportunities MSEs afford. Enshrining leveraging approaches in the MSE bidding, planning, and delivery stages, with meaningful involvement of the local state is just a first step in supporting the redistribution of opportunity in the context of local organizations and MSBs, who too often bear the brunt and significant challenges and disruption associated with the coming of MSEs.

\section{References}

Bason, T., \& Grix, J. (2018). Planning to fail? Leveraging the Olympic bid. Marketing Intelligence and Planning, 36(1), 138-151.

Calvo, S. (2014). London 2012: Missed out on Olympics contracts? A case study of ethnic minority organisations in East London. Local Economy, 29(1-2), 82-97.

Celik, E. (2011). The exclusion of street traders from the benefits of the FIFA 2010 World Cup in South Africa. African Journal of Business and Economic Research, 6(1), 62-86.

Chalip, L. (2004). Beyond impact: A general model for sport event leverage. In B. W. Ritchie \& D. Adair (Ed.), Sport tourism: Interrelationships, impacts and issues (pp. 236252). Clevedon, UK: Channel View Publications.

Chalip, L., \& Leyns, A. (2002). Local business leveraging of a sport event: Managing an event for economic benefit. Journal of Sport Management, 16(2), 132-158.

Department for Business, Innovation, \& Skills. (2012). Business population estimates for the UK and regions 2012. London, UK: UK Government.

Department for Culture, Media, and Sport. (2008). Before, during and after: Making the most of the London 2012 Games. London, UK: Author.

Donaldson, T., \& Preston, L. E. (1995). The stakeholder theory of the corporation: Concepts, evidence, and implications. Academy of Management Review, 20(1), 65-91.

Duignan, M. B., Kirby, S. I., O’Brien, D., \& Everett, S. (2018). From "clone towns" to "slow towns": Examining festival legacies. Journal of Place Management and Development, 11(3), 350-366.

Duignan, M. B., \& McGillivray, D. (2016). How Rio 2016 satisfied the sponsors while leaving room for the people. Retrieved from http://theconversation.com/how-rio2016-satisfied-its-sponsors-while-leaving-room-for-thepeople-64071

Faulkner, B., Chalip, L., Brown, G., Jago, L., March, R., \& Woodside, A. (2000). Monitoring the tourism impacts of the Sydney 2000 Olympics. Event Management, 6(4), 231-246.

Federation of Small Businesses. (2013). Passing the baton: How small businesses have been affected by the London 2012 Games. Retrieved from https://www.fsb.org. uk/docs/default-source/fsb-org-uk/policy/rpu/london/ assets/passingthebaton_fsb_final.pdf 
Foley, M., McGillivray, D., \& McPherson, G. (2012). Policy pragmatism: Qatar and the global events circuit. International Journal of Event and Festival Management, 3(1), 101-115.

Getz, D. (2017). Developing a framework for sustainable event cities. Event Management, 21(5), 575-591.

Glasgow 2014 XX Commonwealth Games. (2014a). Glasgow 2014 food charter. Retrieved from http://www. glasgow2014.com/sites/default/files/documents/PUBCCW\%20Food\%20Charter\%20UPDATE_2014-0408_V.pdf

Glasgow 2014 XX Commonwealth Games. (2014b). Get ready Glasgow (GRG)—Business ready guide. Glasgow, Scotland: Author.

Glasgow 2014 XX Commonwealth Games. (2014c). Ensuring engagement and leaving a legacy: Our approach. Glasgow, Scotland: Author.

Gold Coast 2018 Commonwealth Games Corporation. (2018). Get set for the Games. Queensland, Australia: City of Gold Coast Council.

Gold Coast 2018 XXI Commonwealth Games. (2017). GC2018 food experience. Queensland, Australia: City of Gold Coast Council.

Gold, J. R., \& Gold, M. M. (2008). Olympic cities: Regeneration, city rebranding and changing urban agendas. Geography Compass, 2(1), 300-318.

Gration, D., Raciti, M., Getz, D., \& Andersson, T. D. (2016). Resident valuation of planned events: An event portfolio pilot study. Event Management, 20(4), 607-622.

Grix, J., Brannagan, P. M., Wood, H., \& Wynne, C. (2017). State strategies for leveraging sports mega-events: Unpacking the concept of "legacy.” International Journal of Sport Policy and Politics, 9(2), 203-218.

Hall, C. M. (2006). Urban entrepreneurship, corporate interests and sports mega-events: The thin policies of competitiveness within the hard outcomes of neoliberalism. Sociological Review, 54(s2), 59-70.

Heere, B., Van Der Manden, P., \& Van Hemert, P. (2015). The South Africa World Cup: The ability of small and medium firms to profit from increased tourism surrounding mega-events. Tourism Analysis, 20(1), 39-52.

Horne, J., \& Whannel, G. (2016). Understanding the Olympics (2nd ed.). Abingdon, UK: Routledge.

House of Lords. (2013). Keeping the flame alive: The Olympic and Paralympic legacy. Retrieved from http:// www.publications.parliament.uk/pa/ld201314/ldselect/ ldolympic/78/78.pdf

International Olympic Committee. (2018). Olympic Agenda 2020-Olympic Games: The new norm. Retrieved from https://stillmed.olympic.org/media/Document\%20 Library/Olympic Org/News/2018/02/2018-02-06Olympic-Games-the-New-Norm-Report.pdf

Jones, A., Woolley, J., \& Currie, G. (2015). The London Summer 2012 Olympic Games: Threat of disruption and business reaction. Event Management, 19(2), 187-210.

Jones, C. (2001). Mega-events and host-region impacts: Determining the true worth of the 1999 Rugby World
Cup. International Journal of Tourism Research, 3(3), 241-251.

Kaplanidou, K., Al Emadi, A., Sagas, M., Diop, A., \& Fritz, G. (2016). Business legacy planning for mega events: The case of the 2022 World Cup in Qatar. Journal of Business Research, 69(10), 4103-4111.

Kassens-Noor, E., \& Lauermann, J. (2017). How to bid better for the Olympics: A participatory mega-event planning strategy for local legacies. Journal of the American Planning Association, 83(4), 335-345.

Lauermann, J. (2014). Competition through interurban policy making: Bidding to host megaevents as entrepreneurial networking. Environment and Planning A, 46(11), 2638-2653.

Lockstone-Binney, L., Whitelaw, P., Robertson, M., Junek, O., \& Michael, I. (2014). The motives for ambassadors bidding for international association meetings and events. Event Management, 18(1), 65-74.

London Assembly. (2006). The business of the Games: The opportunities for small and medium sized London firms arising from the 2012 Olympic and Paralympic Games. Retrieved from https://www.london.gov.uk/sites/default/ files/gla_migrate_files_destination/archives/assemblyreports-econsd-olympic_businesses.pdf

London Organizing Committee of the Olympic and Paralympic Games. (2009). London 2012 food vision. Retrieved from http://learninglegacy.independent.gov.uk/ documents/pdfs/sustainability/cp-london-2012-foodvision.pdf

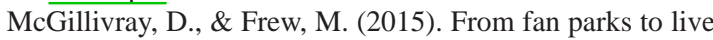
sites: Mega events and the territorialisation of urban space. Urban Studies, 52(14), 2649-2663.

McGillivray, D., \& Turner, D. (2017). Event bidding: Politics, persuasion and resistance. London, UK: Routledge.

McPherson, G., Misener, L., McGillivray, D., \& Legg, D. (2017). Creating public value through parasport events. Event Management, 21(2), 185-199.

Mount, J., \& Leroux, C. (1994). Assessing the effects of a mega-event: A retrospective study of the impact of the Olympic Games in the Calgary business sector. Festival Management and Event Tourism, 2(1), 15-23.

O’Brien, D. (2006). Event business leveraging: The Sydney 2000 Olympic Games. Annals of Tourism Research, 33(1), 240-261.

O’Brien, D., \& Gardiner, S. (2006). Creating sustainable mega event impacts: Networking and relationship development through pre-event training. Sport Management Review, 9(1), 25-47.

Organization for Economic Cooperation and Development. (2008). Local development benefits from staging global events: Achieving the local development legacy from 2012. Retrieved from http://www.oecd.org/regional/leed/ 46207013.pdf

Pappalepore, I., \& Duignan, M. B. (2016). The London 2012 cultural programme: A consideration of Olympic impacts and legacies for small creative organisations in East London. Tourism Management, 54, 344-355. 
Queensland Government. (2017). Ahead of the GamesEvaluation report for the Gold Coast 2018 Commonwealth Games legacy program. Retrieved from https:// www.embracing2018.com/sites/default/files/resource/ ahead-of-the-games-report-nov-2017.pdf

Raco, M., \& Tunney, E. (2010). Visibilities and invisibilities in urban development: Small business communities and the London Olympics 2012. Urban Studies, 47(10), 2069-2091.

Ratnatunga, J., \& Muthaly, S. K. (2000). Lessons from the Atlanta Olympics: Marketing and organisational considerations for Sydney 2000. International Journal of Sport Marketing and Sponsorship, 2(3), 60-78.

Roche, M. (2017). Mega-events and social change: Spectacle, legacy and public culture. Manchester, UK: Manchester University Press.

Rogerson, C. M. (2009). Mega-events and small enterprise development: The 2010 FIFA World Cup opportunities and challenges. Development Southern Africa, 26(3), 337-352.

SEBRAE. (2015). Anuário do Trabalho na Micro e Pequena Empresa 2014. Brasília/DF: Serviço Brasileiro de Apoio às Micro e Pequenas Empresas.

Shaw, C. A. (2008). Five ring circus: Myths and realities of the Olympic Games. Gabriola Island, British Columbia: New Society Publishers.

Singh, N., \& Zhou, H. (2016). Transformation of tourism in Beijing after the 2008 Summer Olympics: An analysis of the impacts in 2014. International Journal of Tourism Research, 18(4), 277-285.

Smith, A. (2010). Leveraging benefits from major events: Maximising opportunities for peripheral urban areas. Managing Leisure, 15(3), 161-180.
Smith, A. (2012). Events and urban regeneration: The strategic use of events to revitalise cities. London, UK: Routledge.

Smith, A. (2018). Animation or denigration? Using urban public spaces as event venues. Event Management, 21(5), 609-619.

Smith, A., \& Fox, T. (2007). From “event-led” to "eventthemed” regeneration: The 2002 Commonwealth Games Legacy Programme. Urban Studies, 44(5-6), 1125-1143.

Spilling, O. R. (1996). Mega event as strategy for regional development: The case of the 1994 Lillehammer Winter Olympics. Entrepreneurship and Regional Development, 8(4), 321-344.

Spilling, O. R. (1998). Beyond intermezzo? On the longterm industrial impacts of mega-events: The case of Lillehammer 1994. Festival Management and Event Tourism, 5(3), 101-122.

Steinbrink, M. (2013). Festifavelisation: mega-events, slums and strategic city-staging - the example of Rio de Janeiro. Journal of the Geographical Society of Berlin, 144(2), 129-145.

Swart, K., \& Bob, U. (2004). The seductive discourse of development: The Cape Town 2004 Olympic bid. Third World Quarterly, 25(7), 1311-1324.

UK Trade \& Investment. (2013). London 2012: Delivering the economic legacy. Retrieved from https://www. gov.uk/government/uploads/system/uploads/attach ment_data/file/295088/London_2012_-_Delivering_ the_Olympic_Legacy.pdf

Williams, P. W., \& Elkhashab, A. (2012). Leveraging tourism social capital: The case of the 2010 Olympic Tourism Consortium. International Journal of Event and Festival Management, 3(3), 317-334. 